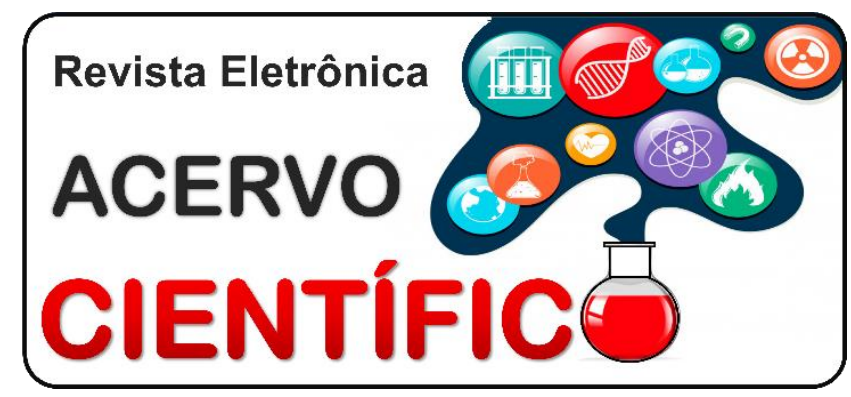

REVISÃO BIBLIOGRÁFICA

Recebido em: 7/2020

Aceito em: 8/2020

Publicado em: $11 / 2020$

\title{
Influência do transplante de células tronco hematopoiéticas na qualidade de vida de pacientes pediátricos
}

\author{
Influence of hematopoietic stem cell transplantation on the quality of life pediatric patients \\ Influencia del trasplante de células madre hematopoyéticas en la calidad de vida de \\ pacientes pediátricos
}

Pedro Antonio Rodrigues Dias ${ }^{1 *}$, Thales Miranda Sales ${ }^{2}$, Crislaine Eduarda de Oliveira ${ }^{3}$, Eduarda de Oliveira Nascimento ${ }^{3}$, Fernanda Mara do Nascimento Almada ${ }^{3}$, Hiann Werner Braun Oliveira de Melo ${ }^{1}$, João Vitor Lisboa Antonietoํ․ Raíssa Gonçalves Pinto ${ }^{1}$, Thaís Vieira da Silva ${ }^{1}$, Yasmin Borges Weber ${ }^{1}$.

Resumo: Este artigo buscou realizar uma revisão narrativa a respeito do impacto do transplante de célulastronco hematopoiéticas (TCTH) na vida dos pacientes transplantados pediátricos, abordando os principais acometimentos a curto e longo prazo, como também os benefícios trazidos pela terapêutica. O TCTH é uma opção de tratamento que vem evoluindo significativamente, graças aos avanços em pesquisas e em tecnologia, sendo uma boa alternativa para pacientes que não obtiveram sucesso em outras condutas. A terapêutica é um procedimento agressivo com possível desencadeamento de consequências físicas e mentais importantes ao paciente. Desse modo, nota-se que a melhor maneira de buscar pela boa qualidade de vida dos pacientes pediátricos transplantados e de seus familiares é a realização de um acompanhamento contínuo de uma equipe multidisciplinar para a vigilância de efeitos tardios, prevenindo os possíveis acometimentos. Assim, em conjunto, deve-se orientar devidamente os pais sobre as possíveis complicações após o procedimento e sobre como lidar com os desafios biopsicossociais e econômicos existentes.

Palavras-chave: Transplante de medula óssea, Qualidade de vida, Crianças.

\begin{abstract}
This article aimed to do a narrative review the impact of hematopoietic stem cell transplantation (HSCT) on the lives of pediatric transplant patients, addressing the main short and long-term problems, as well as the benefits brought by therapy. HSCT is a treatment option that has evolved significantly, thanks to advances in research and technology, being a good alternative for patients who have not been successful in other approaches. The therapy is an aggressive procedure with possible triggering of important physical and mental consequences for the patient. Thus, it is noted that the best way to search for good quality of life for transplanted pediatric patients and their families is to carry out continuous monitoring by a multidisciplinary team for the surveillance of late effects, preventing possible attacks. Thus, together, parents should be properly advised on the possible complications after the procedure and on how to deal with the existing biopsychosocial and economic challenges.
\end{abstract}

Keywords: Bone marrow transplantation, Quality of life, Child.

Resumen: Este artículo buscaba revisar narrativamente el impacto del trasplante de células madre hematopoyéticas $(\mathrm{TCMH})$ en la vida de los pacientes con trasplante pediátrico, abordando los principales

\footnotetext{
${ }^{1}$ Centro Universitário de Caratinga (UNEC), Caratinga - MG. *E-mail: pedrorr.dias99@gmail.com

2 Universidade Federal de Ouro Preto (UFOP), Ouro Preto - MG.

${ }^{3}$ Universidade Federal de Juiz de Fora (UFJF), Juiz de Fora - MG.
} 
problemas a corto y largo plazo, así como los beneficios que brinda la terapia. HSCT es una opción de tratamiento que ha evolucionado significativamente, gracias a los avances en investigación y tecnología, siendo una buena alternativa para pacientes que no han tenido éxito en otros enfoques. La terapia es un procedimiento agresivo con posibles desencadenantes de importantes consecuencias físicas y mentales para el paciente. De ese modo, Se observa que la mejor manera de buscar una buena calidad de vida para los pacientes pediátricos trasplantados y sus familias es llevar a cabo un monitoreo continuo por parte de un equipo multidisciplinario para la vigilancia de los efectos tardíos, evitando posibles ataques. Por lo tanto, juntos, los padres deben ser adecuadamente informados sobre posibles complicaciones después del procedimiento y sobre cómo enfrentar los desafíos biopsicosociales y económicos existentes.

Palabras clave: Transplante de médula ósea, Calidad de vida, Niño.

\section{INTRODUÇÃO}

O transplante de células-tronco hematopoiéticas (TCTH) é um procedimento muito usado para tratar pacientes com diversas doenças, inclusive neoplasias hematológicas, mesmo havendo um risco considerável de desenvolver complicações e efeitos colaterais graves, como o óbito. Apesar disso, esse tratamento oferece a possibilidade de cura para as doenças hematológicas, podendo ser usado como primeira linha de tratamento ou se as outras intervenções falham (KISCH A, et al., 2015; TREMOLADA M, et al., 2018; LJUNGMAN P, et al., 2010).

Dessa forma, o TCTH teve seu uso cada vez mais ampliado para o tratamento terapêutico em diversas condições pediátricas. Em contrapartida, seu uso, a longo prazo, pode gerar sequelas de saúde mental levadas pouco em consideração no estudo dos sobreviventes. Assim, notou-se uma correlação entre pacientes que foram receptores de TCTH e o aparecimento de depressão, ansiedade e outros fatores clínicos, tais como a aplasia de medula, a doença do enxerto contra hospedeiro e complicações infecciosas que alteram a qualidade de vida e a saúde dos pacientes pediátricos (GIUSEPPE G, et al., 2020).

Os pacientes diagnosticados com neoplasia hematológica, bem como outras condições pediátricas, como a aplasia de medula grave e a aplasia pura de células vermelhas, podem fazer o tratamento com transplante de células tronco hematopoiéticas. Esse tratamento é visto como eficaz, porém, de alta complexidade. Sua implantação requer a interação de diversos profissionais da área da saúde, acarretando em quadros de depressão e ansiedade. Portanto, caracteriza como uma atuação dinâmica durante a intervenção de diversos profissionais da área (MARQUES AC, et al., 2017).

O TCTH é um tratamento eventualmente capaz de salvar vidas. O número desses procedimentos está aumentando significativamente e, concomitantemente, as indicações para sua aplicação clínica (SANNERS TS, 2019). Associado ao procedimento do TCTH, nota-se a importância do conceito de qualidade de vida na abordagem do paciente. Sua principal definição, segundo a Organização Mundial de Saúde (OMS), é dita como: "percepção do indivíduo e de sua posição na vida, no contexto de sua cultura e dos sistemas de valores em que vive em relação às suas expectativas, seus padrões e suas preocupações" (WHO, 1997). Esse conceito retrata os fatores psicossociais e econômicos na manutenção da saúde do indivíduo (ALMEIDA MAB, et al., 2012).

Diante do exposto, define-se como objetivo do presente trabalho fazer uma revisão acerca de como o Transplante de Medula Óssea (TMO) pode afetar a qualidade de vida de pacientes pediátricos devido às comorbidades decorrentes do procedimento.

\section{REVISÃO BIBLIOGRÁFICA}

\section{O transplante de células tronco hematopoiética}

O TCTH é uma terapêutica que tem por objetivo tratar diferentes deficiências oncológicas, imunológicas, hemoglobinopatias e doenças malignas que envolvem o sistema hematológico, distúrbios do metabolismo, entre outras. Essa terapêutica é indicada para intervenção em doenças benignas e malignas, levando o paciente e seus familiares a mudanças bruscas em seus hábitos rotineiros, visto que o transplantado fica 
suscetível a infecções, danos psicológicos, complicações em diversos órgãos e em alguns casos, podendo levar ao óbito (BEZERRA WSP, et al., 2017; MAZZA VA, et al., 2016).

Essa terapia é classificada quanto a fonte doadora em autólogo, singênico e alogênico. No TCTH autólogo o doador é o próprio receptor, nesse caso as células do paciente foram coletadas e tratadas para posterior infusão. No transplante singênico o doador e o paciente são gêmeos homozigotos e por fim, o transplante alogênico é aquele em que o doador não é o próprio receptor e também não é gêmeo homozigoto, nesse caso o doador pode possuir ou não possuir laços parentais com o receptor. Para algumas doenças é indicativo como primeira opção de transplante o transplante autólogo e em outras doenças como leucemias agudas é indicado o transplante alogênico (BEZERRA WSP, et al., 2017).

Diversas considerações são analisadas para que o paciente possa obter o melhor desfecho para seu caso clínico. Dentro dessas considerações a idade do paciente, a presença de comorbidades prévias, o prognóstico, o tempo de diagnóstico e até as condições sociais do paciente são verificados para que não haja interferência no tratamento, independentemente do tipo de transplante realizado (MARQUES AC, et al., 2018).

Norkim M, et al. (2019), analisaram 5088 receptores pediátricos após transplante alogênico de células tronco hematopoiéticas de 202 locais diferentes da Center for International Blood and Marrow Transplant Research, e observaram que uma história de doença do enxerto contra o hospedeiro foi relatada em 858 (17\%) pacientes após o TCTH. Além disso, dos 377 óbitos registrados, $110(29 \%)$ tiveram como causa as infecções tardias que contribuíram para um terço de todas as mortes que ocorreram pelo menos 2 anos após - TCTH em pacientes pediátricos. No entanto, cada modalidade de TCTH possui particularidades, com protocolos e esquemas quimioterápicos preestabelecidos conforme a doença e também de acordo com os diferentes graus de complexidade. Para que seja realizado o TCTH é necessário que doador e receptor sejam compatíveis, ou seja, exames como a tipagem de HLA são realizados para observar a compatibilidade desses indivíduos. Dessa forma intercorrências que possam levar ao mau prognóstico do receptor, como as infecções tardias e a doença do enxerto contra hospedeiro, que acontece quando os linfócitos do doador reconhecem o hospedeiro como estranho e tem início um processo imunológico de ataque às células do receptor, são minimizadas (PROENÇA SFFS, et al., 2016; MARQUES AC, et al., 2018).

O TCTH vem se expandindo gradativamente graças aos avanços tecnológicos, novos estudos e descobertas sobre o assunto e aos bons resultados na saúde física de grande parte dos transplantados. Por outro lado, é válido ressaltar sobre as consequências negativas, sendo elas físicas e psicossociais na vida do paciente, de seus familiares, do cuidador e do grupo social em que o paciente se encontra inserido, haja visto que suas necessidades no pós-transplante acarretam mudanças bruscas na rotina e na vivência das pessoas ao seu redor (GOMES IM, et al., 2019).

\section{Indicação ao TCTH}

O transplante de células-tronco hematopoiéticas (TCTH) é uma opção de tratamento para inúmeros pacientes pediátricos. É importante, no entanto, ressaltar que não existem indicações absolutamente padronizadas para esse tratamento, isso é, a indicação estará correta quando a avaliação da sobrevida e a qualidade de vida do paciente forem consideradas melhores com o transplante do que com o tratamento convencional, normalmente quimioterápico (SEBER A, 2009).

As modalidades de transplante e suas respectivas indicações são três: autólogo, alogênico aparentado e alogênico não aparentado. O primeiro tem como objetivo tornar possível a administração de altas doses quimioterápicas em doenças que mostram sensibilidade ao aumento da dose, sendo assim a toxicidade dessas drogas é um fator limitante para o tratamento. Esse modelo de transplante é indicado principalmente para neuroblastoma avançado, tumor de Wilms em segunda remissão, linfomas de Hodgkin em segunda remissão, sarcoma de Ewing em segunda remissão onde tenha havido ressecção completa do tumor, tumor de células germinativas em segunda remissão, meduloblastoma de alto risco em segunda remissão e linfoma não Hodgkin em segunda remissão (CASTRO CG, et al., 2001).

As principais indicações para o modelo de transplante alogênico são as doenças não neoplásicas como a anemia de fanconi, as doenças de acúmulo, a anemia aplástica grave (AAG), as imunodeficiências, a 
osteopetrose, a leucemia mielóide crônica, a talassemia maior, a anemia falciforme, a leucemia linfocítica aguda em primeira remissão, a leucemia mielóide aguda em primeira remissão, os linfomas não Hodgkin em segunda ou terceira remissão, a mielofibrose maligna aguda e as síndromes mielodisplásicas. Existe, além disso, um modelo de transplante mais raro chamado singênico que ocorre entre irmãos gêmeos idênticos e possui as mesmas indicações do TCTH alogênico (CASTRO CG, et al., 2001).

\section{Procedimento TCTH}

Para que seja realizado o TCTH testes para verificar o estado de saúde do doador e receptor são feitos. O paciente deve se encontrar em condições clínicas adequadas, sem disfunção grave de órgãos ou sistemas. Ademais exames devem ser realizados para observar a compatibilidade entre doador e receptor. $O$ teste do sistema HLA é o principal nesse quesito, esse sistema é responsável por codificar a identidade imunológica dos indivíduos que é expressa na superfície celular. Ele fica localizado no braço curto do cromossomo 6 e contém mais de 200 genes que formam o principal complexo de histocompatibilidade (MHC). O HLA segue regras de herança mendeliana simples, assim, irmãos têm $25 \%$ de chance de serem HLA idênticos e além disso, essas proteínas desempenham um papel fundamental nas reações imunológicas recíprocas quando células-tronco hematopoiéticas alogênicas são transplantadas (CASTRO CG, et al., 2001; SINGH AK e MCGUIRK JP, 2016).

Quando há confirmação da compatibilidade e confirmação do futuro transplante o receptor é submetido ao processo de condicionamento que é o processo de imunossupressão, levando o paciente a uma aplasia completa da medula para que ele possa receber a nova medula. Este processo ocorre através de irradiação e/ou quimioterapia. O uso de antibióticos pode ser indicado, de acordo com cada protocolo institucional, como uma terapia profilática porque nos meses seguintes ao transplante há o risco de ocorrência de infecções devido a imunossupressão causada no condicionamento. Dessa forma fica implícito que muitos medicamentos são utilizados nessa fase (BEZERRA WSP, et al., 2017).

É de suma importância para a ocorrência do transplante que haja uma equipe multidisciplinar treinada e especializada nesse tipo de procedimento. A coleta de células tronco hematopoiéticas pode ser realizada por aspirado de medula óssea ou por coleta de sangue periférico via aférese. Para coletar as células da medula óssea do doador, ele deve ser hospitalizado e sob o uso da anestesia geral, várias punções e aspirações são realizadas na crista ilíaca, retirando a quantidade de medula óssea necessária para o transplante. A medula deve ser colocada em um recipiente adequado que contenha anticoagulante, e logo após, passa por um processo de filtração para que ocorra a remoção de espículas ósseas e gordura. Fatores que estimulam colônias de granulócitos, como a filgrastima, são usados nas coletas realizadas em sangue periférico. Ademais em pacientes que passam pelo transplante autólogo, pode ser combinada a uma quimioterapia prévia. Equipamentos de aférese são utilizados para a coleta das células progenitoras hematopoiéticas, também se faz necessário que seja realizado um acesso venoso com bom calibre. (CASTRO CG, et al., 2001).

Na maioria dos serviços que praticam o TCTH singênico e alogênico, imediatamente após a retirada das células progenitoras de sangue periférico e da medula óssea, elas devem ser infundidas por meio de cateter venoso central. É importante que se faça o teste de compatibilidade do sistema $A B O$, caso haja incompatibilidade entre o doador e o receptor, antes da infusão é feita a retirada das hemácias da medula óssea, e quando indicado, faz-se plasmaférese no receptor para evitar reações transfusionais severas. Quando o transplante é autólogo há o pré-condicionamento do paciente, ademais é realizado o estímulo de células tronco, após isso as células são coletadas e tratadas, então o paciente é submetido ao condicionamento para receber as células coletadas (CASTRO CG, et al., 2001).

\section{Benefícios}

No que tange os pacientes pediátricos com doenças hematológicas e determinadas neoplasias, o transplante de medula óssea (TMO) é uma opção de tratamento. Faz-se necessário, acompanhar tais pacientes após o transplante até a fase adulta, a vigilância contínua dos efeitos tardios pode ajudar a prevenir ou mitigar as consequências físicas e psicológicas a longo prazo do TCTH (BERBIS J, et al., 2013; BEVANS M, et al., 2017). 
A qualidade de vida relacionada à saúde (QVRS) tem uma tremenda importância para pacientes pediátricos com TCTH, pois é realizada para curar doenças de outra forma incuráveis e, se bem-sucedida, a expectativa de vida dos receptores é comparável à população pediátrica em geral (ZAJAC-SPYCHA O, et al., 2019). O transplante é uma esperança de tratamento e cura para várias doenças, o TMO em pacientes pediátricos se tornou recorrente ao longo dos anos e proporcionou maior probabilidade de pacientes, com leucemia por exemplo, sobreviverem livres da doença por anos após o transplante (CHOW EJ, et al., 2016; VROOMAN LM, et al., 2017). Mais de 1 milhão de TCTHs foram realizados globalmente até o momento desde o seu início como uma modalidade de tratamento, com aumentos substanciais no número de transplantes alogênicos nas últimas 3 décadas (GRATWOHL A, et al., 2015).

O prognóstico dos pacientes que fizeram transplantes alogênicos aparentados e autólogos progrediu, nos últimos tempos, sobretudo devido à melhoria no tratamento de suporte e consequente diminuição da mortalidade relacionada ao procedimento. Na pediatria, o melhor plano continua sendo o diagnóstico antecipado e a prevenção da recidiva por meio da avaliação criteriosa e constante da enfermidade residual mínima e do quimeirismo após os transplantes. A rapidez no direcionamento para o transplante, a diminuição do tempo preciso tanto para identificar doadores como de espera pelo leito especializado, também podem ajudar muitos pacientes pediátricos que têm avanço da doença ou perdem a vida por complicações ao esperar que o transplante seja realizado (SEBER A, 2009).

\section{Complicações e observações a longo prazo}

Nos estudos de Castro CG, et al. (2001), são enumeradas diversas complicações nos primeiros meses pós transplante, como a aplasia da medula óssea, doença enxerto contra hospedeiro (DECH) aguda e crônica, complicações infecciosas que compreendem as bacterianas, fúngicas e virais, complicações gastrointestinais da qual se destaca a doença veno-oclusiva hepática (DVOH), e também as doenças gênito-urinárias que podem levar a uma insuficiência renal. Uma esfera pouco abordada na literatura trata-se da qualidade de vida relacionada à saúde (QVRS) a longo prazo após o processo do transplante, principalmente quando esse quesito é voltado para as alterações psicossociais dos pacientes. Sabendo que os indivíduos são considerados sobreviventes a longo prazo quando ultrapassam a marca de dois anos pós-TCTH, observa-se que o Brasil tem desafios que dificultam uma estratégia bem-sucedida de acompanhamento a longo prazo dessas pessoas, dentre eles, os estressores econômicos, infraestrutura insuficiente, influências políticas e sociais (MARINHO DH, et al., 2019).

Na revisão sistemática realizada por Giuseppe GD, et al. (2020), é retratado complicações ligadas diretamente à saúde mental dos pacientes pediátricos que passaram pelo TCTH. Neste estudo, enfatizam que a ansiedade e depressão podem afetar os transplantados em até décadas após o transplante e, que essas pessoas precisam ser acompanhadas por uma equipe multidisciplinar para evitar que essas manifestações se tornem ainda mais graves. Ainda, foi constatado que a presença de múltiplas condições crônicas de saúde, sexo feminino e $\mathrm{DECH}$ são importantes fatores de risco para ansiedade, depressão e baixa QVRS em crianças.

Os pacientes pediátricos estão estritamente ligados aos seus responsáveis. Os pais muitas vezes abdicam de suas carreiras, tem demasiados custos com as despesas médicas e enfrentam o medo de lidar com a possível morte de seu filho, então, esses muitas vezes estão propensos a desenvolver o transtorno do estresse pós-traumático (TEPT). Além do mais, algumas famílias ainda precisam lidar com mais um processo hospitalar quando o transplante é halogênico e, nessa condição de internação hospitalar, o irmão doador também fica suscetível a desenvolver TEPT. Porém, esse transtorno tem uma tendência a diminuir nos irmãos durante o tempo, enquanto nas mães a tendência é que esse aumente, pois elas precisam dar apoio físico, emocional e lidar com as mudanças em suas próprias rotinas (ÇOBAN OG, et al., 2017).

Um estudo realizado em Vietnã por Liem NT, et al. (2018), com 30 crianças através da aplicação de questionários para avaliar a QVRS da criança antes e depois do transplante traz reflexões acerca dos efeitos do TCTH em crianças com paralisia cerebral. Resultados discutem a melhoria do tônus muscular e da função motora desses pacientes e mostra que a QVRS desses indivíduos após o procedimento aumentou significativamente em todos os domínios, bem como a melhoria do bem-estar e aceitação social. 
Conforme um estudo observacional realizado com 55 participantes, constatou-se a importância do apoio familiar para os pacientes que se submeteram ao TCTH, uma vez que nas fases hospitalares estes precisam se sentir seguros. Assim sendo, os primeiros 100 dias pós transplante devem ser acompanhados com atenção, pois nesse período crítico do tratamento, há um comprometimento físico da QVRS do paciente com possíveis quadros de infecção e complicações agudas já citadas previamente (MARQUES AC, et al., 2017). Ademais, para que esses dias pós-transplante possam ocorrer com o devido apoio e acompanhamento dos parentes, é importante educar os relacionados não apenas sobre a necessidade de sobrevivência do paciente, mas sobre os próximos desafios físicos, emocionais e sociais que possam vir a acontecer na vida do transplantado (BECKMAN NB, et al., 2017).

Em termos gerais, é notável que os transplantados podem enfrentar diversos desafios, mas que se acompanhados de perto por uma equipe multidisciplinar e ter apoio dos que vivem com ele, os índices de qualidade de vida podem melhorar muito. Ao enfrentar um isolamento social durante o tratamento, algumas consequências físicas do transplante, gastos financeiros e demais adaptações podem mudar a maneira que o paciente enfrenta o processo saúde-doença, no entanto, com apoio, seu sofrimento poderá ser minimizado e os benefícios do TCTH se destacaram ao fim do tratamento (PROENÇA SFFS, et al., 2016).

\section{CONSIDERAÇÕES FINAIS}

É perceptível a importância do TCTH em pacientes pediátricos cujas doenças são incuráveis em outro tratamento. Essa terapêutica evolui gradativamente em função de avanços tecnológicos associado aos novos estudos realizados. Porém, verifica-se a necessidade de investigação dos possíveis malefícios desenvolvidos pelo TCTH, visto que são observadas não só complicações físicas a curto e longo prazo no transplantado, como também consequências relacionadas à saúde mental do paciente e de seus familiares. Portanto, tornase necessária uma orientação adequada para que os pais adotem a melhor conduta para lidar com os possíveis desafios biopsicossociais e econômicos após o transplante. Aliado a isso, é imprescindível o acompanhamento multidisciplinar rigoroso a criança, para que seja possível a minimização de sintomas físicos e emocionais, proporcionando a ela e a sua família uma melhor qualidade de vida.

\section{REFERÊNCIAS}

1. ALMEIDA MAB, et al. Qualidade de vida: definições, conceitos e interfaces com outras áreas de pesquisa. São Paulo (SP): Escola de Artes, Ciências e Humanidades da Universidade de São Paulo; 2012.

2. BACKMANN NB, et al. Quality of life among boys with adrenoleukodystrophy following hematopoietic stem cell transplant. Child Neuropsychology, 2017; 24:7, 986-998

3. BERBIS J, et al. Uma coorte francesa de sobreviventes de leucemia infantil: impacto do transplante de células-tronco hematopoiéticas no estado de saúde e na qualidade de vida. Transplante de medula óssea Biol. $2013 ; 19$ (7): 1065 1072.

4. BEVANS M, et al. Iniciativa dos efeitos tardios do transplante de células hematopoiéticas dos Institutos Nacionais de Saúde: o relatório do grupo de trabalho sobre resultados centrados no paciente. Transplante de medula óssea Biol. 2017; 23 (4): 538-551.

5. BEZERRA WSP, et al., Clinical and epidemiological profile of children and adolescents submitted to the hematopoietic cell transplantation. 2019; 35(5)

6. CASTRO CG, et al., Transplante de medula óssea e transplante de sangue de cordão umbilical em pediatria. 2001; $77,(5), 345-360$

7. CHOW EJ, et al. Recomendações de vigilância de efeitos tardios entre sobreviventes de transplante de células hematopoiéticas na infância: um relatório do Grupo de Oncologia Infantil. Transplante de Medula Sanguínea Biol 2016; 22 (5): 782-795.

8. ÇOBAN OG, et al. Post-traumatic stress disorder and health-related quality of life in the siblings of the pediatric bone marrow transplantation survivors and post-traumatic stress dirsorder in their mothers. Pediatr Transplant. 2017; 21(6):10

9. GIUSEPPE GD, et al. Anxiety, depression, and mental health-related quality of life in survivors of pediatric allogeneic hematopoietic stem cell transplantation: a systematic review. Springer Nature. 2020; 55, 1240-1254

10. GOMES IM, et al., Cuidados realizados pelo familiar cuidador da criança em pós-transplante de células-tronco hematopoiéticas. 2019, vol. 27

11. GRATWOHL A, et al. Um milhão de transplantes de células-tronco hemopoiéticas: um estudo observacional retrospectivo. Lancet Haematol. 2015; 2: e91 - 100 
12. KISCH A, et al. Being a haematopoietic stem cell donor for a sick sibling: Adult donors' experiences prior to donation. Eur J Oncol Nurs. 2015;19(5):529-535.

13. LIEM NT, et al. The effects of bone morrow mononuclear cell transplantation on the quality of life of children with cerebral palsy. Health and Quality of Life Outcomes, 2018; 16(1):164

14. LJUNGMAN P, et al. European Group for Blood and Marrow Transplantation. Allogeneic and autologous transplantation for haematological diseases, solid tumours and immune disorders: current practice in Europe 2009. Bone Marrow Transplant. 2010;45(2):219-234.

15. MARINHO DH, et al. The challenge of long-term follow-up of survivors of childhood acute leucemia after hematopoietic stem cell tranplantation in resource-limited countries: A single-center report from Brazil. Willy Periodicals, 2020.

16. MARQUES AC, et al. Qualidade de vida nos primeiros seis meses pós-transplante de células-tronco hematopoiéticas. Texto Contexto Enferm. 2017; p. 26

17. MAZZA VA, et al. Vivência de famílias de crianças e adolescentes submetidos ao Transplante de Células-Tronco Hematopoéticas. 2016; 18:e119

18. NORKIN M, et al. Characteristics of Late Fatal Infections after Allogeneic Hematopoietic Cell Transplantation. Biol Blood Marrow Transplant. 2019;25(2):362-368.

19. PROENÇA SFFS, et al. Qualidade de vida de pacientes pós-transplante de células tronco hematopoéticas com doença do enxerto-hospedeiro. Revista da Escola de Enfermagem da USP, 2016;50(6):953-960.

20. SANNERS TS, et al. Angústia e qualidade de vida em díades de pacientes e cuidadores que enfrentam transplante de células-tronco: identificando sobreposição e contribuições únicas. Suporte ao Câncer. $2019 ; 27$ (6): 2329 - 2337.

21. SEBER A. O transplante de células-tronco hematopoéticas na infância: situação atual e perspectivas. Rev. Bras. Hematol. Hemoter. 2009;31(Supl. 1):59-67.

22. SINGH AK e MCGUIRK JP, Allogeneic Stem Cell Transplantation: A Historical and Scientific Overview.

23. TREMOLADA M, et al. Health-related quality of life in AYA cancer survivors who underwent HSCT compared with healthy peers. Eur J Cancer Care (Engl). 2018;27(6):e12878.

24. VROOMAN LM, et al. Sobrevivência e efeitos tardios após transplante alogênico de células hematopoiéticas para malignidade hematológica com menos de três anos de idade. Transplante de medula óssea. Biol. $2017 ; 23$ (8): 13271334.

25. WACHOWIAK J, et al. Desenvolvimento e corrente uso do transplante de células-tronco hematopoiéticas em crianças e adolescentes na Polônia: relatório do grupo de estudo pediátrico polonês para transplante de células-tronco hematopoiéticas da Sociedade Polonesa de Oncologia e Hematologia Pediátrica. Transfus Apher Sci. $2018 ; 57$ (3): $316-322$.

26. WHO: World Health Organization. WHOQOL Measuring quality of life. The world health organization quality of life instruments (The WHOQOL 100 and the WHOQOL Bref). Geneva, 1997.

27. ZAJAC-SPYCHA O, et al. American Society for Transplantation and Cellular Therapy. Elsevier Inc. 2019. 